\title{
[URE3] and [PSI] are Prions of Yeast and Evidence for New Fungal Prions
}

Daniel C. Masison, Herman K. Edskes, Marie-Lise Maddelein, Kimberly L. Taylor and Reed B. Wickner*

National Institutes of Health, Bethesda, MD 20892-0830, USA

\section{Abstract}

[URE3] and [PSI] are two non-Mendelian genetic elements discovered over 25 years ago and never assigned to a nucleic acid replicon. Their genetic properties led us to propose that they are prions, altered self-propagating forms of Ure2p and Sup35p, respectively, that cannot properly carry out the normal functions of these proteins. Ure2p is partially proteaseresistant in [URE3] strains and Sup35p is aggregated specifically in [PSI] strains supporting this idea. Overexpression of Hsp104 cures [PSI], as does the absence of this protein, suggesting that the prion change of Sup35p in [PSI] strains is aggregation. Strains of [PSI], analogous to those described for scrapie, have now been described as well as an in vitro system for [PSI] propagation. Recently, two new potential prions have been described, one in yeast and the other in the filamentous fungus, Podospora.

\section{Background}

The yeast non-Mendelian genetic element, [URE3], was discovered by Francois Lacroute in 1971 as a dominant 'mutation' making cells able to take up ureidosuccinate so that they could grow in spite of a block in aspartate transcarbamylase, whose product is ureidosuccinate (1, 76; see Fig. 1). A 'non-Mendelian' genetic element is characterized by its failing to segregate at meiosis (as do chromosomal gene differences), and its efficient transfer by the transfer of cytoplasm from cell to cell. [URE3] segregates irregularly in meiosis in most crosses $(1,76)$.

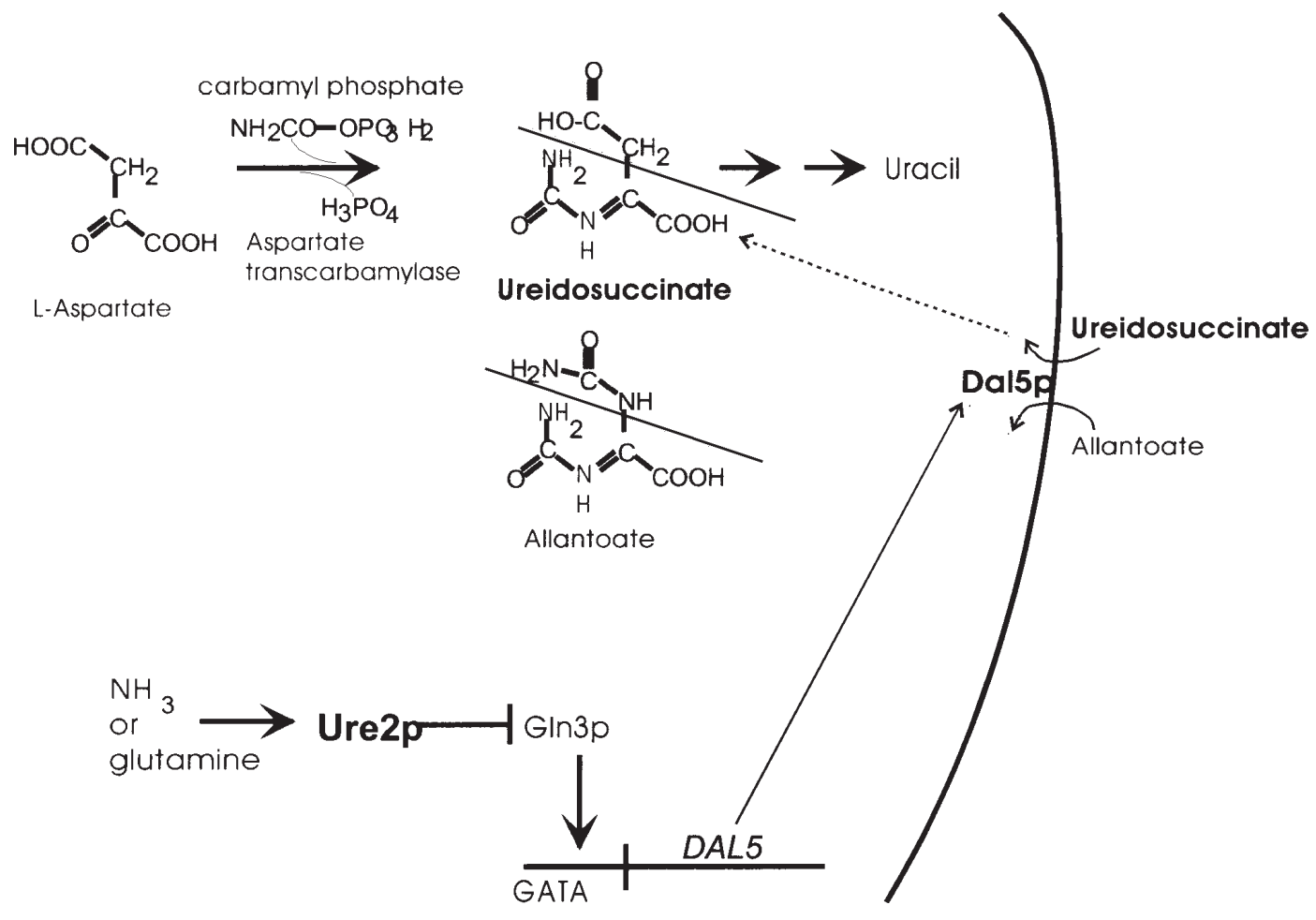

Figure 1. Ure2p, Ureidosuccinate, uracil biosynthesis and nitrogen regulation. Yeast normally prefers ammonia or glutamine as a nitrogen source, and URE2 is involved in repressing the synthesis of proteins for utilization of poor nitrogen sources when a good nitrogen source such as ammonia is available (Fig. 1 , 1 , reviewed in 66,67$)$. Ure2p acts by blocking the transcription activation by $\operatorname{Gln} 3 p(68,69,70,17,71)$. The similarity of structure of ureidosuccinate to allantoate results in ureidosuccinate being recognized by Dal5p, the allantoate uptake protein (72). Because allantoate is a poor nitrogen source for yeast, Dal5p is subject to Ure2p control, and thus so is ureidosuccinate uptake (Fig. 1, ref. 73). [URE3] and ure2 are scored by testing growth of aspartate transcarbamylase mutants (ura2) on synthetic medium with ammonium as nitrogen source and ureidosuccinate in place of uracil. Modified from ref 74. 
Reversible Curing

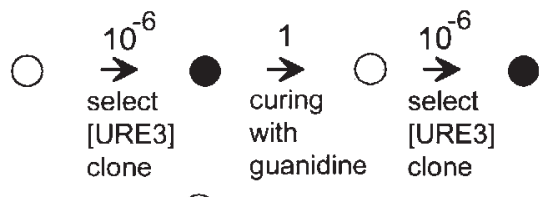

$$
\begin{aligned}
& \bigcirc=\text { [ure-o] clone } \\
& =\text { [URE3] clone }
\end{aligned}
$$

Ure2p overproduction $\rightarrow$ higher frequency of [URE3]

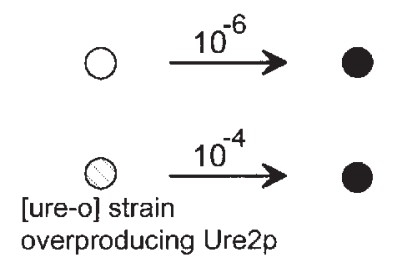

Phenotype relationship of prion and gene

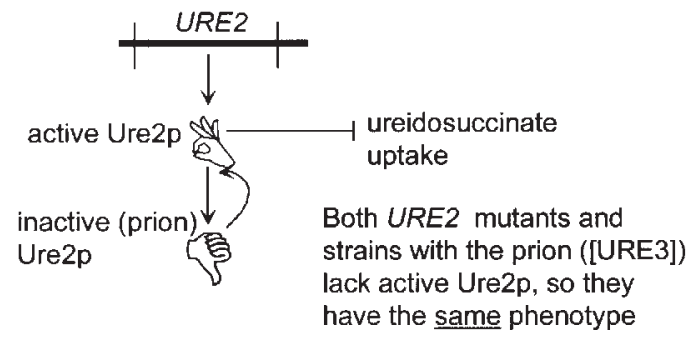

Figure 2. Genetic properties expected of a yeast prion (10).

Aigle and Lacroute found that [URE3] was transfered efficiently by cytoplasmic mixing (cytoduction) (2). In the same screen in which he found [URE3], Lacroute also isolated recessive mutations in a chromosomal gene that he named URE2. [URE3] was shown to be unrelated to mitochondrial DNA (1) and the dsRNA yeast viruses (3). Remarkably, propagation of [URE3] did not occur in a ure2 mutant (2). This struck us as unusual because the phenotype of the presence of [URE3] and the defect in ure 2 were essentially the same. In contrast, the phenotype of the presence of M dsRNA (killer) and of recessive mak mutants unable to propagate M dsRNA (non-killer) are opposites (for review see 4). There are other possible explanations for this, none of which proved to be true as we shall discuss, but the possibility that [URE3] was a prion form of Ure2 $p$ first arose from our reaction to this result of Aigle and Lacroute.

[PSI] is also a non-Mendelian genetic element of yeast, discovered in 1965 by Brian Cox (5). [PSI] makes weak nonsense suppressor tRNAs strong, and strong suppressors lethal $(5,6)$. [PSI] at first seemed specific for ochre suppressors, those suppressing the UAA codon, but later was found able to assist the bypass of any terminator (7). Efforts to identify [PSI] with one of the known yeast non-chromosomal nucleic acid replicons were unsuccessful $(8,3)$.

\section{Expected Properties of a Yeast Prion}

Yeast viruses are widespread in natural isolates, with most strains carrying most viruses. However, no yeast (or other fungal) viruses are known to spread by an extracellular route. Spread is always via the cell-cell fusion that occurs in mating or heterokaryon formation, and these elements are found as non-Mendelian genetic elements (reviewed in ref. 9). An infectious protein of yeast should likewise be found as a non-Mendelian genetic element. We proposed several features that make a non-Mendelian genetic element a strong candidate to be a prion (10; Fig. 2).

\section{Reversible Curability}

If it is possible to cure a yeast prion, it should nonetheless be possible to isolate some cells in the progeny of the cured, purified prion-less strain that have again acquired the prion. This is because the same spontaneous alteration of the normal form that gave rise to the prion in the first place can happen again, at some low frequency. This is not true for nucleic acid replicons, like viruses and plasmids.

\section{Overproduction of the Normal Form Increases the} Frequency with Which the Prion Form Arises

Since the prion form arises from the normal form, if there is more of the normal form, the frequency with which the prion change occurs should be higher, almost regardless of the mechanism of the prion change. Thus, overproducing the normal protein from a high-copy plasmid should increase the frequency with which the prion arises.

\section{The Prion Produces a Similar Phenotype to Mutation of a Gene Needed for its Propagation}

This criterion was suggested (10) in spite of the fact that this is not the case for PrP. Mice lacking PrP do not die of scrapie (11); in fact they live a normal lifespan and are immune to infection by scrapie $(11,12)$. Scrapie is due to the accumulation of an abnormal form of PrP which no longer is degraded as is the normal form (13). In growing yeast, it seems unlikely that gross accumulation of anything could be a problem. Rather, it should be the absence of the normal form of the protein that produces the phenotype. Cells carrying the prion form of the protein make the normal form, but quickly convert it into the prion (inactive) form. Cells carrying a mutation in the gene for the normal form do not make the normal protein from the start. Thus, it is expected that the phenotype of cells carrying the prion should closely resemble the phenotype of cells with a mutation in the normal form and the gene for the normal form will be necessary for the propagation of the prion. In fact, this is the way to find the gene encoding a protein one suspects of being a prion. Among chromosomal genes needed for its propagation, one whose mutant phenotype is the same as that of the presence of the putative prion is the candidate for the gene for the protein.

In contrast, the phenotype of the presence of a nucleic acid replicon is the opposite of that of a defect in a chromosomal gene needed for its replication. For example, mutants unable to propagate the killer toxin-encoding segment of the yeast dsRNA virus (mak mutants unable to propagate $M$ dsRNA) are non-killers, but the presence of the M dsRNA makes cells killers. 


\section{Genetic Properties of [URE3] Indicate it is a Prion}

[URE3] is efficiently cured by growth in the presence of 5 $\mathrm{mM}$ guanidine on rich medium (M. Aigle, cited in 14, 10), but a cured, purified strain can still give rise to clones carrying [URE3] at some low frequency (10). This is reversible curability. The requirement of [URE3] for URE2 for its propagation $(2,10)$ and the similar phenotype of ure2 mutants and [URE3] strains suggests that [URE3] is a prion form of Ure2p (10). Finally, overproduction of Ure2 $p$ leads to an increase in the frequency with which [URE3] arises $(10,15)$. Thus, [URE3] satisfies all three genetic expectations for a prion of Ure2p.

\section{Further Evidence that [URE3] is a Prion}

Because PrP was discovered as a protease-resistant protein found in purified preparations of scrapie agent (16), and because protease-sensitivity is a good non-specific probe of protein structure, we examined Ure2p by western blot in extracts of isogenic [URE3] and wild-type strains (15). We found that Ure2p was unchanged in either migration on SDS polyacrylamide gels or in its amount. However, on treatment with proteinase K, while the Ure2p in extracts of wild-type strains was completely digested at the earliest time point (1 $\mathrm{min})$, that in extracts of [URE3] strains was partially resistant to this treatment (15). Fragments of 30 to $32 \mathrm{kDa}$ persisted for up to 25 minutes of digestion. This indicates that the Ure2 protein is altered
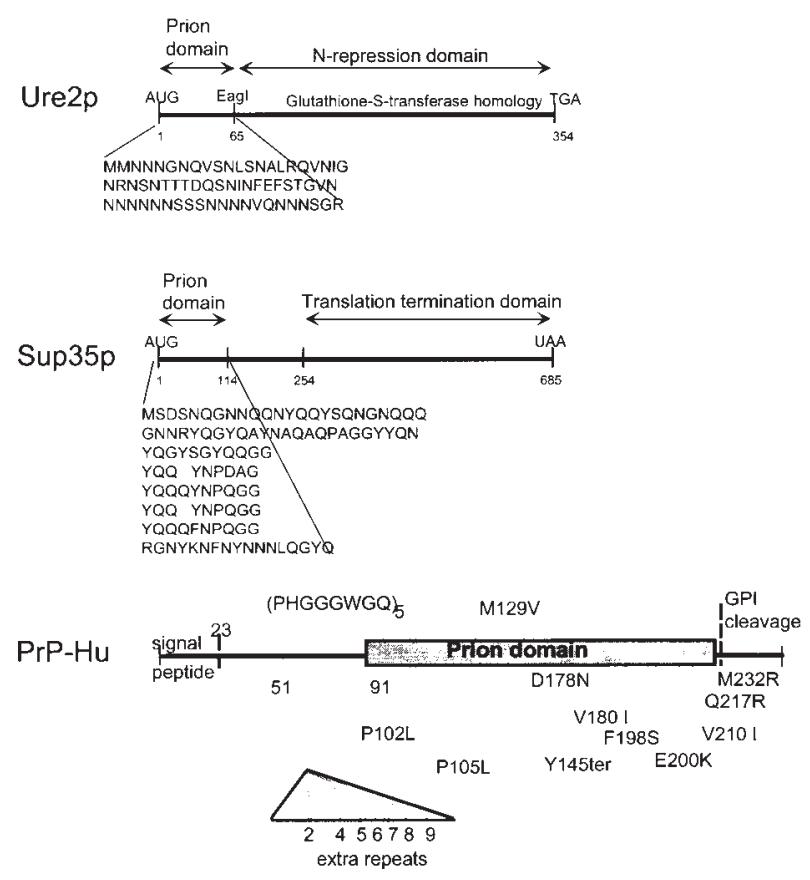

Figure 3. Domains of Ure2p and Sup35p, in comparison with PrP. The part of Ure2p and Sup35p needed for induction and propagation of [URE3] and [PSI], respectively, are the $\mathrm{N}$-terminal parts, rich in asparagine and glutamine $(15,23,34,25)$. The central part of PrP is necessary for propagation of scrapie. Induction of scrapie by overproduction of part or all of PrP has not yet been demonstrated. There is no homology between either yeast system and PrP. Modified from ref. 74 . in either its structure or its association with other proteins in [URE3] strains. While this can happen to many proteins under many circumstances, and this is not specific evidence of a prion, it is a prediction of the prion explanation of [URE3] and supports this hypothesis. [URE3] strains have derepressed nitrogen metabolism, and it was possible that the protease resistance was due to a change of Ure2p involved in its regulatory function, not a prion related change. That this is not the case was shown by examining the proteinase K-sensitivity of Ure2p in extracts of wildtype and [URE3] strains grown on proline (a derepressing medium) in comparison with those grown on ammonia as the nitrogen source (75). Proline derepression of nitrogen metabolism did not alter the protease sensitivity of Ure2p.

\section{The Prion Domain of [URE3]}

Overexpression of Ure2p results in a 20- to 100-fold increase in the frequency with which [URE3] appears in a wild-type strain $(10,15)$. When various fragments of Ure2p were overexpressed and their ability to complement ure2 $\Delta$ and their ability to induce [URE3] appearance were examined, it was found that the $\mathrm{N}$-terminal 65 residues of the protein are sufficient to induce [URE3] at 100-fold the frequency of the same overexpression of the full-length gene (15; Fig. 3). Deletion of the same N-terminal 65 residues of Ure2p produced a C-terminal fragment that was able to carry out the nitrogen regulation function of Ure2p, but was unable to induce [URE3]. In fact, the background spontaneous [URE3] events were not seen in this case. We inferred that this C-terminal fragment is insensitive to the presence of [URE3] (15). Thus, this Nterminal 65 residues is both necessary in cis for a molecule to be changed into the prion form, and sufficient (when overproduced) to induce the change in trans in normal Ure2p. We therefore call this the prion domain of Ure2p (Fig. 3).

Coschigano and Magasanik noted that Ure2p has significant homology to a number of glutathione Stransferases (17). All of this homology is located in the Cterminal nitrogen regulation domain (Fig. 3). However, glutathione S-transferase activity has not yet been reported in Ure2p. The N-terminal prion domain of Ure2p is very asparagine-rich ( $40 \%$ of residues), a feature that is doubtless related to the [URE3] prion phenomenon.

\section{Mechanism of [URE3] Prion Propagation}

The fact that overproduction of the prion domain induces [URE3], while overproduction of the C-terminal nitrogen regulatory domain does not, suggests the model shown in Fig. 4 (15). The C-terminal domain not only does not induce [URE3], but it prevents one observing the usual spontaneous [URE3] events (15). This suggests that the C-terminal domain cannot propagate the [URE3] change and that it is interactions between the prion domains of separate molecules that propagate the [URE3] change.

\section{Genetic Properties of [PSI] Indicate it is a Prion}

[PSI] can be cured by growth of cells in high osmotic strength media (18), or by growth in the presence of $5 \mathrm{mM}$ guanidine (19). However, in both cases, curing is reversible in that colonies carrying [PSI] may again be isolated from cured purified strains $(19,20)$. Thus, $[\mathrm{PSI}]$ shows reversible 
A.
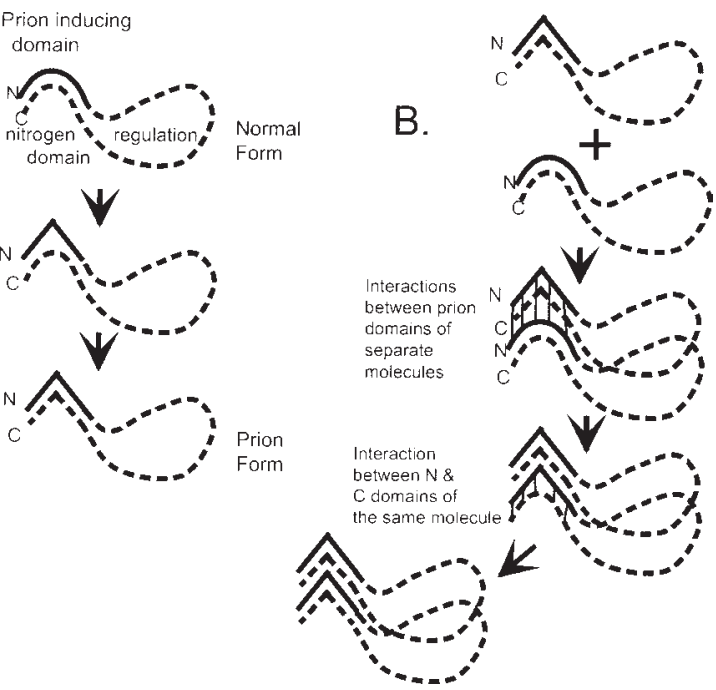

Figure 4. Proposed Mechanism of prion generation and propagation (15 74). The prion form arises by a spontaneous change of the prion (N-terminal) domain of a molecule. This change results in inactivation of the $\mathrm{C}$-terminal domain of the same molecule through some direct interaction. The transmission of the prion change from one molecule to another is by interaction between the $\mathrm{N}$-terminal domains of two molecules. The altered $\mathrm{N}$-terminal domains then interact with the C-terminal domains of their respective molecules. This model is applicable to [PSI] as well (see 23, 34)

curability. It is important to note that for neither [PSI] nor [URE3] is curability by guanidine evidence for a prion. The concentration of guanidine used is too low to be likely to have any denaturation effects on the proteins in the cell. Moreover, poliovirus replication is well known to be blocked by low concentrations of guanidine, an effect that is mediated by the RNA replicase (21). It is the reversibility of curing that is a sign of a prion (10).

The phenotype of [PSI] (14) is like that of sup35 mutants, increased efficiency of nonsense suppressors (22). And SUP35 is necessary for the propagation of [PSI] $(23,24)$. This is the relation of phenotypes and genes expected for a prion and the chromosomal gene for its normal form (10) (Fig. 5). Furthermore, overproduction of Sup35p results in a 100-fold increase in the frequency with which [PSI] arises (20). This induction of [PSI] appearance is not due to the presence of the SUP35 gene in high copy, nor to the increase of SUP35 mRNA, but the the elevated Sup35 protein (25). Thus, [PSI], like [URE3], has all three genetic properties expected for a yeast prion (Fig. 2).

\section{Further evidence that [PSI] is a Prion}

Sup35p is one of the subunits of the translation termination factor $(26,27,28)$, whose role is to recognize the termination codon, and release the peptidyl tRNA from the ribosome, cleaving the nascent peptide from the tRNA. Early evidence that termination was abnormal in [PSI] strains came from studies in which the yeast in vitro translation system was used to examine readthrough of termination codons of heterologous mRNAs in the presence of known suppressor tRNAs $(29,30)$. As expected, it was found that termination of translation (for all three nonsense codons) was much more efficient in extracts of a $\left.\mathrm{PSI}^{+}\right]$ strain than those of a [psi-] strain. However, unexpectedly, mixing extracts of $\left[\mathrm{PSI}^{+}\right]$and $\left[\mathrm{psi}^{-}\right]$strains showed that the [psi-] extract was dominant in vitro although it was recessive in vivo (29). This was unexpected if $\left[\mathrm{PSI}^{+}\right]$is dominant in vivo because it encodes a protein. But if [PSI] is a prion form of Sup35p, then the [psi-] extract should have active Sup35p and the $\left[\mathrm{PSI}^{+}\right]$extract should not, and so the $\left[\mathrm{psi}^{-}\right.$ ] extract should be dominant in vitro. Of course, if the prion form of Sup35p were converting the normal form into the prion form in vitro, then $\left[\mathrm{PSI}^{+}\right]$might be dominant in vitro as well. This interpretation (31) of these results supports the prion hypothesis for [PSI].

Since [psi-] was dominant in vitro (29), it was possible to purify the component of a [psi-] extract that promoted translation termination. This was found to be a ribosome-associated protein $(30)$, like Sup35p $(32,33)$.

Recently, it has been shown that Sup35p is aggregated in $\left[\mathrm{PSI}^{+}\right]$strains, but not in [psi $\left.{ }^{-}\right]$strains (34). Sup35p in extracts of [PSI] strains sediments rapidly, whereas that in extracts of [psi ${ }^{-}$cells sediments as the expected heterodimer with Sup45p (34). As the N-terminal domain of Sup35p is required for propagation of [PSI] (23, see below), it was found that the Sup35p aggregates from [PSI] strains interact specifically with the same N-terminal part (34). In addition, Sup35p in [PSI] strains was shown to be more resistant to digestion with protease than that in [psi-] strains, a further sign that alteration of Sup35p is associated with [PSI]. Fluorescence microscopy of cells

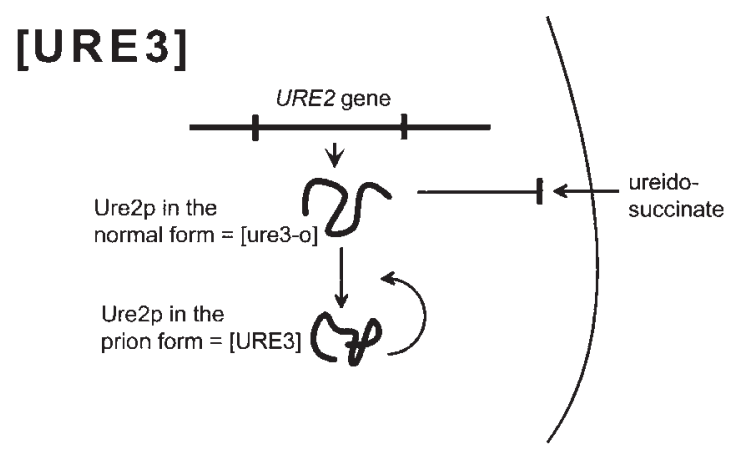

[PSI]

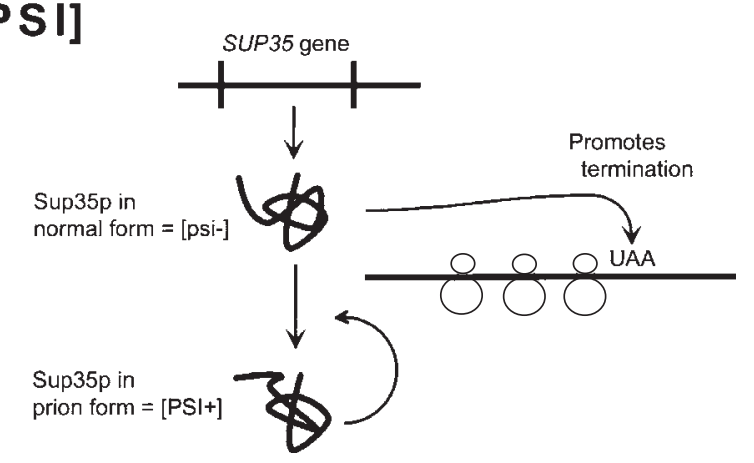

Figure 5. [URE3] and [PSI] as prion forms of Ure2p and Sup35p, respectively (10). The prion form arises spontaneously, but, having done so, is propagated because it can change the normal form of the protein into the prion form. The prion form is unable to carry out its normal function, giving rise to the phenotypes of [URE3] or [PSI]. These phenotypes are similar to the phenotypes of recessive mutations of the URE2 and SUP35 genes. The URE2 and SUP35 genes are necessary for propagation of [URE3] and $[\mathrm{PSI}]$ respectively. 
expressing a green fluorescent protein-Sup35p fusion protein also showed that in strains with [PSI], Sup35p was largely aggregated, but it was evenly distributed in wildtype cells (35).

\section{The Prion Domain of [PSI]}

Sup35p may be divided into three domains: the $\mathrm{N}$-terminal 154 residues which includes the octapeptide repeats and is rich in glutamine and asparagine, the middle 99 residues, and the C-terminal essential domain that has homology with elongation factor EF-1a and functions with Sup45p in translation termination $(36,37,26,28,27)$. Deletion analysis showed that the N-terminal domain is both necessary for propagation of [PSI] (23) and sufficient (when overproduced) to induce the appearance of [PSI] in a wild - type strain (25) (Fig. 4). This is in close parallel to the results with [URE3] and the critical role of the amino terminal domain of Ure2p discussed above. The prion domain of Sup35p has multiple octapeptide repeats similar to those found in the $\mathrm{N}$-terminal part of PrP, but the latter are not needed for scrapie propagation, so this similarity may be incidental. However, the Sup35p prion domain is asparagine-glutamine rich like the Ure2p prion domain.

\section{Hsp104p is Critical for [PSI] Propagation}

Chernoff and Ono (38) isolated a high copy plasmid that cured [PSI]. Its sequence showed that it encoded Hsp104 (39), a chaperone that is capable of disaggregating proteins that have been denatured by a heat shock (40). Overproduction of Hsp104 from a GAL1 promoter also cured [PSI] (39). Surprisingly, deletion of the HSP104 gene also resulted in the loss of [PSI] (39). That Hsp104 overexpression can cure [PSI] both supports the idea that [PSI] is a prion, and that the prion change is one of conformation, rather than one of covalent modification. Two interpretations have been proposed for the loss of [PSI] in hsp104 mutants. One is that this chaperone must partially unfold the normal form of Sup35p in order for the prion form to convert it to the prion form (39). The other interpretation is that, since the [PSI] form of Sup35p is an aggregate, this aggregate must be partially disaggregated in order to assure that each of the daughter cells receive some of the aggregate (34). If there is just one big aggregate, one of the daughter cells will receive no aggregate and will have, in effect, lost [PSI].

\section{In vitro [PSI] Propagation}

Recently, Paushkin et al. (41) have developed an in vitro system in which Sup35p purified from a [PSI] strain can initiate a self-perpetuating aggregation of normal Sup35p. They found that the aggregated Sup35p in extracts of [PSI] strains could initiate the aggregation of the soluble Sup35p in [psi] strains. This reaction could then be used as the seed for a new reaction which would then proceed as in the first one. Paushkin et al. were able to amplify the original aggregated form 200 - fold and there seems no reason why the reaction could not continue (41). The product of the reaction showed the same rapid sedimentation and proteinase $\mathrm{K}$ resistance as did the seed material.

Highly purified Sup35p from a [PSI] strain was able to act as the seed for the prion change of soluble Sup35p purified from a hsp104D [psi] strain. This result suggests that the role of Hsp104 in [PSI] propagation is not directly in the conversion of Sup35p to the altered form, but rather, as these authors previously suggested, in guaranteeing the segregation of some aggregated form to each of the daughter cells (34, see above).

This is the first in vitro prion propagation system which can continue indefinitely. The biological aspects are clearly reproduced by this system in that the substrate is the normal Sup35p purified from [psi-] yeast, the initiating material is the aggregated highly purified Sup35p from $\left[\mathrm{PSI}^{+}\right]$yeast, the product seems to resemble the seed material and the $\mathrm{N}$-terminal domain shown to be critical for prion propagation in vivo is also critical in vitro (41).

\section{Strains of [PSI]}

While the strain of animal is important in determining the course of scrapie infection, different isolates of the scrapie agent, obtained from different diseased sheep by infection of mice, could be distinguished by differences in the incubation period before clinical disease developed, and by the regions of the brain showing pathology $(42,43,44$, reviewed by 45). These scrapie agent strains show important differences in the same strain of mice. Recently, distinguishable strains of [PSI], showing different efficiencies of suppression in the same yeast strain, have been described (25). These [PSI] strains also showed differences in the ease with which they could be cured by growth in the presence of guanidine, or by overproduction of Hsp104 (25). The [PSI] strain conferring stronger suppression was less easily cured by both agents.

This result is important because one of the strongest arguments advanced against the prion hypothesis for scrapie has been the existence of multiple strains of the scrapie agent, thought to be explicable only by a replicating nucleic acid. The results from Leibman's lab on strains of [PSI] support the notion that strains may be a general property of prions (25).

\section{Evidence for a New Prion, Pin+(for [PSI] Inducibility)}

As if it were not interesting enough that Sup35p can show one prion phenomenon, Sue Leibman and coworkers have now found what appears to be a second prion determined by a different part of the same molecule (46). Although [PSI] is induced by overexpression of Sup35p $(20,25)$, it has now been found that not all strains show this effect (46). Some strains do not detectably develop [PSI] even when Sup35p is overexpressed. The ability to be converted to $\left[\mathrm{PSI}^{+}\right]$by overexpression of Sup35p is called the Pin ${ }^{+}$ phenotype, and the inability, $\mathrm{Pin}^{-}$. Crosses indicate that $\mathrm{Pin}^{+}$is dominant and is inherited as a non-Mendelian genetic element (46). Unlike [PSI] itself, $\mathrm{Pin}^{+}$is independent of the N-terminal domain of Sup35p. $\mathrm{Pin}^{+}$is often eliminated by growth of cells on $5 \mathrm{mM}$ guanidine or by elimination of Hsp104 expression, suggesting that $\mathrm{Pin}^{+}$is, like [PSI] and [URE3], a prion (46). Although there is as yet no direct evidence that $\mathrm{Pin}^{+}$is an alteration of Sup35p, the effects of $\mathrm{Pin}^{+}$are so far on Sup35p's activity or modifiability, suggesting this conclusion. Since the C-terminal part of Sup35p is essential for growth, this will be tricky to prove. 
Derkatch et al. suggest that $\mathrm{Pin}^{+}$is a selfpropagating alteration of the C-terminal part of Sup35p that affects the availability of the N-terminal domain for interaction with the $\mathrm{N}$-terminal domains of Sup35p molecules in the [PSI] conformation (46).

\section{A Prion of Podospora Determines Heterokaryon Incompatibility}

Podospora anserina is a filamentous fungus. The filamentous ascomycetes have two modes of cell fusion. Mating involves cell fusion followed by nuclear fusion and leads to meiosis. Mating generally requires the presence of opposite alleles at the mating type locus. Another mode of cell fusion is heterokaryon formation. Branches of two fungal colonies meet and fuse without nuclear fusion occurring. Cytoplasmic mixing occurs, however, and so a cytoplasmic genetic element present in one colony can invade another colony. In Podospora, this heterokaryon formation requires identity of alleles at the het loci. When there are different alleles at a het locus, the fused cells die and form a barrier between the two colonies. This reaction is called heterokaryon incompatibility or vegetative incompatibility.

One such locus is the het-s locus of Podospora anserina. The alleles at this locus are het-S and het-s. The het-s locus encodes a 289 residue protein that differs at 14 positions between het-s and het-S (47). However, a single residue, at position 33 in the protein, $\mathrm{H}$ in het- $\mathrm{S}$ and $P$ in het-s, is the dominant determinant of het-S or het-s behavior in vegetative incompatibility with a smaller influence of residue 23 (48).

It was observed by Rizet in 1952 (49) that genetically het-s cells could have two different phenotypes. They can show the usual vegetative incompatibility reaction, in which case they are said to show the [Het-s] phenotype, or they can show neutral behavior, fusing with either het-S or with het-s strains (Table 1). This neutral behavior is denoted [Het-s*]. Deletions of the het-s locus $\left(\right.$ het- $\left.s^{\circ}\right)$ are also neutral, and show no defects in growth or any aspects of the life cycle (50).

The [Het-s] trait behaves as a non-Mendelian genetic element (51). 1) It is transmitted to all the meiotic progeny instead of segregating like a chromosomal gene. 2) When a heterokaryon is made between a [Het-s] colony and a [Het-s* colony, the [Het-s] trait spreads throughout what had been the [Het-s* colony and is found in hyphae that lack the nuclei of the [Het-s] parent strain.

That [Het-s] represents a prion state of the protein encoded by het-s is indicated by several lines of evidence (52).

- [Het-s] can be cured with $8 \%$ efficiency by forming spheroplasts and regenerating them. From the cured $[$ Het-s*] clones can again be isolated spontaneous [Hets] derivatives (53). This is reversible curing.

- Overproduction of the het-s protein induces the conversion from [Het-s*] to [Het-s] (52).

- The [Het-s] trait cannot be propagated in het-s $s^{0}$ strains (52), but the relation of phenotypes is not the same as for [URE3] and [PSI]. The het- $S^{\circ}$ strains are neutral and anastomose with either het-s or het-S strains. In contrast, het-s [Het-s] strains show the incompatibility reaction with het-S strains. This is, like the relation of the Prnp gene and scrapie, that of a chromosomal gene necessary for propagation of a nucleic acid replicon and the presence of the replicon. It is consistent with [Het$\mathrm{s}$ ] being a prion state of the het-s protein, but does not provide evidence that this is the case.

- The het-s protein is present at the same concentration in [Het-s] and [Het-s $\left.{ }^{\star}\right]$ strains, but is more proteaseresistant in the [Het-s] strains, a finding suggestive of a prion (52).

\section{The Podospora Prion, Apoptosis and Vegetative Incompatibility}

Vegetative incompatibility is a widespread phenomenon in filamentous fungi, and it has been the subject of extensive genetic analysis. This phenomenon is viewed as a normal part of the fungal life cycle, rather than as a disease. Thus, it is stiking to find that an apparently normal fungal function depends on the presence of a prion. Although [URE3] and [PSI] can be advantageous to the cell under certain special circumstances, it seems unlikely that they are really adaptive. Both, like scrapie, appear to be diseases. Heterokaryon incompatibility appears designed to limit the strains with which a given strain exchanges cytoplasm, and therefore infectious elements, all of which in fungi are cytoplasmic genetic elements (reviewed in ref. 9). It is particularly striking that Podospora enlists the aid of one such infectious element, [Het-s] to guard it against others. Another view of the [Het-s] prion and the vegetative incompatibility is that it represents an apoptosis-like phenomenon. Viral infection of animal cells induces

Table 1. Podospora Anserina Vegetative Incompatibility Reactions

\begin{tabular}{|c|c|c|c|c|}
\hline Genotype & $\begin{array}{l}\text { non-Mendelian } \\
\text { element }\end{array}$ & $\begin{array}{l}\text { Reaction with } \\
\text { het-s [Het-s] }\end{array}$ & $\begin{array}{l}\text { Reaction with } \\
\text { het-s [Het-s*] }\end{array}$ & $\begin{array}{l}\text { Reaction with } \\
\text { het-S }\end{array}$ \\
\hline het-s & none $=\left[\right.$ Het-s $\left.{ }^{*}\right]$ & hyphal fusion & hyphal fusion & hyphal fusion \\
\hline het-s & [Het-s] & hyphal fusion & hyphal fusion & incompatibility \\
\hline het-S & none & incompatibility & hyphal fusion & hyphal fusion \\
\hline$h e t-s^{o}$ & none & hyphal fusion & hyphal fusion & hyphal fusion \\
\hline
\end{tabular}

The het-s ${ }^{\circ}$ strain cannot propagate the [Het-s] non-Mendelian genetic element. See text for discussion and references. [Het-s] is the non-Mendelian genetic element apparently equivalent to the presence of a prion form of the protein encoded by het-s. [Het-s*] is the absence of the prion. 
programmed cell death whose purpose is to limit the spread of the infection. Perhaps vegetative incompatibility has some of the same flavor, with the [Het-s] prion prompting apoptosis of Podospora.

\section{Evidence that [URE3] is a Self-Propagating Amyloidosis of Ure2p}

Fusion proteins of Ure2p with green fluorescent protein show an aggregated distribution in the cytoplasm of yeast cells carrying the [URE3] prion, in cells that do not have the prion an even distribution is seen (77). Fusion of GFP to just the $\mathrm{C}$-terminal domain, which genetic evidence shows cannot undergo the prion change, shows only the even distribution, even in prion-containing cells (77).

The prion domain of Ure2p (Ure2 $p^{1-65}$ ) was synthesized chemically and found to spontaneously form $45 \AA$ diameter amyloid filaments in vitro (78). As is typical of amyloid, these filaments are high in B-sheet content, resistant to protease digestion and show the yellow-green birefringence on staining with Congo red typical of amyloid (78). The Ure $2 \mathrm{p}^{1-65}$ prion domain fragment can promote filament formation by the native soluble full-length Ure2p purified from wild-type yeast cells (78). The prion domain fragment and the full length native molecule form a $200 \AA$ diameter cofilament with equimolar amounts of the two components. This cofilament formation occurs under conditions where the native Ure2p is stably soluble in the absence of the prion domain peptide. Cofilament formation is highly specific in that the Ure $2 \mathrm{p}^{1-65}$ peptide does not induce cofilament formation by proteins other than Ure2p. Nor does $A B^{1-42}$, the major component of the amyloid filaments of Alzheimer's disease, form cofilaments with Ure2p. These cofilaments again have all the properties of amyloid (78). The cofilaments can act as a seed for $400 \AA$ diameter amyloid filament formation by a large excess of native full length Ure2p (78).

Three lines of evidence suggest that this amyloid formation is the molecular basis of the [URE3] prion phenomenon: 1) The pattern of protease-resistant fragments seen with the Ure2p amyloid formed in vitro (78) is the same as that seen for Ure2p in extracts of [URE3]containing cells (15). 2) It is the prion domain of Ure2p that promotes amyloid formation in vitro. 3) The aggregation of Ure2p in [URE3] strains can be explained by amyloid fiber formation under this condition. However, it will be important to isolate Ure2p from [URE3] cells and determine whether it is in the form of amyloid or not.

\section{Evidence that [PSI] is a Self-Propagating Amyloidosis of Sup35p}

Sup35p is aggegated in extracts of [PSI $\left.{ }^{+}\right]$strains (34), and a fusion of GFP to the prion domain of Sup35p appears aggregated in vivo specifically in [PSI ${ }^{+}$cells (35).

Extracts of $\left[\mathrm{PSI}^{+}\right]$cells show a self-propagating aggregation of the Sup35p from uninfected cells (41). The chemically synthesized prion domain of Sup35p spontaneously forms filaments in vitro that have all of the properties of amyloid (79). Moreover, the full length Sup35p made in $E$. coli and solubilized with urea forms filaments in vitro which are high in -sheet and whose formation is seeded specifically by extracts of $\left[\mathrm{PSI}^{+}\right]$cells (80). While full length native Sup35p has not been shown to form amyloid, and the in vivo state of Sup35p in $\left[\mathrm{PSI}^{+}\right]$strains has not been documented, the evidence suggests that amyloid formation by Sup35p is responsible for the $\left[\mathrm{PSI}^{+}\right]$ trait.

\section{Comparisons of [URE3] and [PSI] with Scrapie}

The extreme UV-resistance of the scrapie agent indicated to Alper that it might infect without an essential nucleic acid (54). This finding prompted the first clear description of the prion idea, by Griffith who proposed, "the sub-units can only polymerize by utilizing 'condensation nuclei' of polymer which are already there" (55), essentially the crystal seed form of the modern 'protein-only' hypothesis. That spontaneous, inherited and infectious forms of Creutzfeldt-Jakob disease are all infectious for monkeys (56) argues for the prion idea, but was not interpreted in this way until much later. Griffith's idea was given substance in 1982 when Prusiner discovered $\operatorname{PrP}(16)$. The PrP gene $(57,58)$ was shown $(59)$ to be the same as the gene controlling scrapie incubation period in mice (Sinc) identified by Dickinson in 1968. The demonstration that the PrP sequence controls scrapie infection (e.g., refs. 60, 61 ), and that PrP is necessary for both the disease and propagation of the scrapie agent (12), proved that $\operatorname{PrP}$ is central to the infectious process.

In spite of this and other evidence summarized elsewhere in this volume, there remains some question that the altered PrP is the sole component of the scrapie agent. PrP is highly aggregated in scrapie material, and it is virtually impossible to completely purify it. Moreover, infectivity is not precisely correlated with protease-resistant PrP. For example, infectious material apparently lacking PrP-res has been reported (62). Evidence that overexpression of either normal or mutant PrP induces scrapie has been at best equivocal $(63,64)$. Finally, in spite of many attempts, PrP made from a cDNA clone in various microorganisms has never been shown to be infectious for mice (e.g., 65). All of the evidence for the critical role of PrP in scrapie show that it is necessary, none show that it is sufficient.

The evidence for [URE3] and [PSI] being prions is in many ways better than that for PrP. The genetic evidence for both yeast systems is very strong. It is of course not surprising that it is easier to do genetics in yeast than in mice. The fact that purified scrapie agent is composed largely of PrP is a critical piece of evidence favoring the prion idea, and development of infection systems for the yeast systems would be a very important step. The [PSI] in vitro propagation system appears even better than the scrapie in vitro system because the reaction can continue indefinitely, but it is critical to show (in both systems) that new infectious material is being generated.

\section{Conclusions}

The genetic criteria that we have developed for yeast prions are now being applied to other systems, leading to a reinterpretation of long-known phenomena in accord with the prion concept. Studies of the yeast and fungal prion systems have dramatically changed the general view of prions. 
- Prion phenomena are much more widespread than had been previously shown.

- Prions can be the basis of inherited characters.

- The genetic evidence for prions in yeast is far stronger than has been possible so far in mammals.

- Proof of involvement of chaperones in prion propagation is now available thanks to work on the yeast system. Identification of other involved cellular components promises to be far simpler in yeast.

- It may be possible, using yeast, to develop plate assays for agents that induce or that cure prions.

- Using yeast and fungal genetics, it should be possible to find out what other proteins affect generation, propagation or curing of prions.

\section{Further Reading}

Material in this review has been reprinted (with permission) from:

Harris, D.A. Prions: Molecular and Cellular Biology. Horizon Scientific Press, Wymondham, UK

\section{References}

1. Lacroute, F. 1971. Non-Mendelian mutation allowing ureidosuccinic acid uptake in yeast. J. Bacteriol. 106:519 - 522.

2. Aigle, M., and F. Lacroute. 1975. Genetical aspects of [URE3], a nonMendelian, cytoplasmically inherited mutation in yeast. Molec. Gen. Genet. 136:327 - 335.

3. Leibowitz, M. J., and R. B. Wickner. 1978. Pet18: a chromosomal gene required for cell growth and for the maintenance of mitochondrial DNA and the killer plasmid of yeast. Mol Gen Genet. 165:115-121.

4. Wickner, R. B. 1996. Double-stranded RNA viruses of yeast. Microbiologcial Reviews. 60:250 - 265.

5. Cox, B. S. 1965. PSI, a cytoplasmic suppressor of super-suppressor in yeast. Heredity. 20:505 - 521

6. Cox, B. S. 1971. A recessive lethal super-suppressor mutation in yeast and other PSI phenomena. Heredity. 26:211 - 232.

7. Palmer, E., J. Wilhelm, and F. Sherman. 1979. Phenotypic suppression of nonsense mutants in yeast by aminoglycoside antibiotics. Nature. 277:148 - 150

8. Young, C. S. H., and B. S. Cox. 1972. Extrachromosomal elements in a super-suppression system of yeast. II. Relations with other extrachromosomal elements. Heredity. 28:189 - 199.

9. Wickner, R. B. 1996. Viruses of yeasts, fungi and parasitic microorganisms, p. 557 - 585. In B. N. Fields, D. M. Knipe, and P. M. Howley (ed.), Fields Virology, third ed, vol. 1. Raven Press, New York.

10. Wickner, R. B. 1994. Evidence for a prion analog in S. cerevisiae: the [URE3] non-Mendelian genetic element as an altered URE2 protein. Science. 264(22 April 1994):566 - 569.

11. Büeler, H., M. Fischer, Y. Lang, H. Bluethmann, H. P. Lipp, S. J. DeArmond, S. B. Prusiner, M. Aguet, and C. Weissmann. 1992. Normal development and behavior of mice lacking the neuronal cell-surface PrP protein. Nature. 356:577 - 582.

12. Büeler, H., A. Aguzzi, A. Sailer, R.-A. Greiner, P. Autenried, M. Aguet, and C. Weissmann. 1993. Mice devoid of PrP are resistant to Scrapie. Cell. 73:1339 - 1347.

13. Caughey, B., and G. J. Raymond. 1991. The scrapie-associated form of PrP is made from a cell surface precursor that is both proteaseand phospholipase-sensitive. J. Biol. Chem. 266:18217 - 18223.

14. Cox, B. S., M. F. Tuite, and C. S. McLaughlin. 1988. The Psi factor of yeast: a problem in inheritance. Yeast. 4:159 - 179.

15. Masison, D. C., and R. B. Wickner. 1995. Prion-inducing domain of yeast Ure2p and protease resistance of Ure2p in prion-containing cells. Science. 270:93 - 95.

16. Bolton, D. C., M. P. McKinley, and S. B. Prusiner. 1982. Identification of a protein that purifies with the scrapie prion. Science. 218:1309 1311.

17. Coschigano, P. W., and B. Magasanik. 1991. The URE2 gene product of Saccharomyces cerevisiae plays an important role in the cellula response to the nitrogen source and has homology to glutathione Stransferases. Mol. Cell. Biol. 11:822 - 832.

18. Singh, A. C., C. Helms, and F. Sherman. 1979. Mutation of the nonMendelian suppressor [PSI] in yeast by hypertonic media. Proc. Natl. Acad. Sci. USA. 76:1952 - 1956.
19. Tuite, M. F., C. R. Mundy, and B. S. Cox. 1981. Agents that cause a high frequency of genetic change from $\left[p s i^{+}\right]$to $\left[p s i^{-}\right]$in Saccharomyces cerevisiae. Genetics. 98:691 - 711.

20. Chernoff, Y. O., I. L. Derkach, and S. G. Inge-Vechtomov. 1993. Multicopy SUP35 gene induces de-novo appearance of psi-like factors in the yeast Saccharomyces cerevisiae. Curr. Genet. 24:268 - 270.

21. Tamm, I., and H. J. Eggers. 1963. Specific inhibition of replication of animal viruses. Science. 142:24 - 33.

22. Hawthorne, D. C., and R. K. Mortimer. 1968. Genetic mapping of nonsense suppressors in yeast. Genetics. 60:735 - 742.

23. TerAvanesyan, A., A. R. Dagkesamanskaya, V. V. Kushnirov, and V. N. Smirnov. 1994. The SUP35omnipotent suppressor gene is involved in the maintenance of the non-Mendelian determinant $\left[\mathrm{psi}^{+}\right]$in the yeast Saccharomyces cerevisiae. Genetics. 137:671 - 676.

24. Doel, S. M., S. J. McCready, C. R. Nierras, and B. S. Cox. 1994. The dominant PNM2 mutation which eliminates the [PSI] factor of Saccharomyces cerevisiae is the result of a missense mutation in the SUP35 gene. Genetics. 137:659 - 670.

25. Derkatch, I. L., Y. O. Chernoff, V. V. Kushnirov, S. G. Inge-Vechtomov, and S. W. Leibman. 1996. Genesis and variability of [PS/] prion factors in Saccharomyces cerevisiae. Genetics. 144:1375 - 1386.

26. Frolova, L., X. LeGoff, H. H. Rasmussen, S. Cheperegin, G. Drugeon, M. Kress, I. Arman, A.-L. Haenni, J. E. Celis, M. Philippe, J. Justesen, and L. Kisselev. 1994. A highly conserved eukaryotic protein family possessing properties of polypeptide chain release factor. Nature. 372:701- 703 .

27. Zhouravleva, G., L. Frolova, X. LeGoff, R. LeGuellec, S. IngeVectomov, L. Kisselev, and M. Philippe. 1995. Termination of translation in eukaryotes is governed by two interacting polypeptide chain release factors, eRF1 and eRF3. EMBO J. 14:4065 - 4072.

28. Stansfield, I., K. M. Jones, V. V. Kushnirov, A. R. Dagkesamanskaya, A. I. Poznyakovski, S. V. Paushkin, C. R. Nierras, B. S. Cox, M. D. Ter-Avanesyan, and M. F. Tuite. 1995. The products of the SUP45 (eRF1) and SUP35 genes interact to mediate translation termination in Saccharomyces cerevisiae. EMBO J. 14:4365 - 4373.

29. Tuite, M. F., B. S. Cox, and C. S. McLaughlin. 1983. In vitro nonsense suppression in $\left[\mathrm{psi}^{+}\right]$and $[\mathrm{psi}]$ cell-free lysates of Saccharomyces cerevisiae. Proc. Natl. Acad. Sci. USA. 80:2824 - 2828.

30. Tuite, M. F., B. S. Cox, and C. S. McLaughlin. 1987. A ribosomeassociated inhibitor of in vitro nonsense suppression in [psi-] strains of yeast. FEBS Lett. 225:205 - 208.

31. Wickner, R. B., D. C. Masison, and H. K. Edskes. 1995. [PSI] and [URE3] as yeast prions. Yeast. 11:1671 - 1685 .

32. Eustice, D. C., L. P. Wakem, J. M. Wilhelm, and F. Sherman. 1986. Altered 40S ribosomal subunits in omnipotent suppressors of yeast. J. Mol. Biol. 188:207 - 214.

33. Didichenko, S. A., M. D. TerAvanesyan, and V. N. Smirnov. 1991. Ribosome-bound EF-1 alpha-like protein of yeast Saccharomyces cerevisiae. Eur. J. Biochem. 198:705 - 711

34. Paushkin, S. V., V. V. Kushnirov, V. N. Smirnov, and M. D. TerAvanesyan. 1996. Propagation of the yeast prion-like $\left[\mathrm{psi}^{+}\right]$ determinant is mediated by oligomerization of the SUP35-encoded polypeptide chain release factor. EMBO J. 15:3127 - 3134.

35. Patino, M. M., J.-J. Liu, J. R. Glover, and S. Lindquist. 1996. Support for the prion hypothesis for inheritance of a phenotypic trait in yeast. Science. 273:622 - 626 .

36. Wilson, P. G., and M. R. Culbertson. 1988. SUF12 suppressor protein of yeast: a fusion protein related to the EF-1 family of elongation factors. J. Mol. Biol. 199:559 - 573.

37. TerAvanesyan, M. D., V. V. Kushnirov, A. R. Dagkesamanskaya, S. A. Didichenko, Y. O. Chernoff, S. G. Inge-Vechtomov, and V. N. Smirnov. 1993. Deletion analysis of the SUP35 gene of the yeast Saccharomyces cerevisiae reveals two non-overlapping functional regions in the encoded protein. Mol. Microbiol. 7:683 - 692.

38. Chernoff, Y. O., and B.-I. Ono. 1992. Dosage-dependent modifiers of PSI-dependent omnipotent suppression in yeast. In A. J. P. Brown, M. F. Tuite, and J. E. G. McCarthy (ed.), Protein synthesis and targeting in yeast. Springer-Verlag, Berlin.

39. Chernoff, Y. O., S. L. Lindquist, B.-I. Ono, S. G. Inge-Vechtomov, and S. W. Liebman. 1995. Role of the chaperone protein Hsp104 in propagation of the yeast prion-like factor $\left[\mathrm{psi}^{+}\right]$. Science. 268:880 884.

40. Parsell, D. A., A. S. Kowal, M. A. Singer, and S. Lindquist. 1994. Protein disaggregation mediated by heat-shock protein Hsp104. Nature. 372:475 - 478 .

41. Paushkin, S. V., V. V. Kushnirov, V. N. Smirnov, and M. D. TerAvanesyan. 1997. In vitro propagation of the prion-like state of yeast Sup 35 protein. Science 277: $381-383$. 
42. Dickinson, A. G., and V. M. H. Meikle. 1969. A comparison of some biological characteristics of the mouse-passaged scrapie agents, $22 \mathrm{~A}$ and ME7. Genet. Res. 13:213 - 225.

43. Dickinson, A. G., and V. M. H. Meikle. 1971. Host-genotype and agent effects in scrapie incubation: change in allelic interaction with different strains of agent. Mol. Gen. Genet. 112:73 - 79.

44. Fraser, H. 1973. Scrapie in mice: agent-strain differences in the distribution and intensity of grey matter vacuolation. J. Comp. Pathol. 83:29 - 40 .

45. Bruce, M. E., and H. Fraser. 1991. Scrapie strain variation and its implications. Cur. Topics in Microbiol. Immunol. 172:125 - 138.

46. Derkatch, I. L., M. E. Bradley, P. Zhou, Y. O. Chernoff, and S. W. Liebman. 1997. Genetic and environmental factors affecting the de novo appearance of the $\left[\mathrm{PS}^{+}\right]$prion in Saccharomyces cerevisiae. Genetics. 147: 507 - 519.

47. Turcq, B., M. Denayrolles, and J. Begueret. 1990. Isolation of two alleles incompatibility genes $s$ and $S$ of the fungus Podospora anserina. Curr. Genet. 17:297 - 303.

48. Deleu, C., C. Clave, and J. Begueret. 1993. A single amino acid difference is sufficient to elicit vegetative incompatibility in the fungus Podospora anserina. Genetics. 135:45 - 52.

49. Rizet, G. 1952. Les phenomenes de barrage chez Podospora anserina: analyse genetique des barrages entre les souches $\mathrm{s}$ et $\mathrm{S}$. Rev. Cytol. Biol. Veg. 13:51 - 92

50. Turcq, B., C. Deleu, M. Denayrolles, and J. Begueret. 1991. Two allelic genes responsible for vegetative incompatibility in the fungus Podospora anserina are not essential for cell viability. Mol. Gen. Genet. 288:265 - 269.

51. Beisson-Schecroun, J. 1962. Incompatibilte cellulaire et interactions nucleo-cytoplasmiques dans les phenomenes de barrage chez Podospora anserina. Ann. Genet. 4:3 - 50.

52. Coustou, V., C. Deleu, S. Saupe, and J. Begueret. 1997. The protein product of the het-s heterokaryon incopatibility gene of the fungus Podospora anserina behaves as a prion analog. Proc. Natl. Acad. Sci. USA. 94: 9773 - 9778.

53. Belcour, L. 1975. Neurospora Newsletter. 23:26 - 27.

54. Alper, T., W. A. Cramp, D. A. Haig, and M. C. Clarke. 1967. Does the agent of scrapie replicate without nucleic acid? Nature. 214:764 766.

55. Griffith, J. S. 1967. Self-replication and scrapie. Nature. 215:1043 1044.

56. Gajdusek, D. C., C. J. Gibbs, and M. Alpers. 1967. Transmission and passage of exterimental "kuru" to chimpanzees. Science. 155:212 214.

57. Oesch, B., D. Westaway, M. Walchli, M. P. McKinley, S. B. Kent, R Aebersold, R. A. Barry, P. Tempst, D. B. Templow, L. E. Hood, S. B. Prusiner, and C. Weissmann. 1985. A cellular gene encodes scrapie PrP 27-30 protein. Cell. 40:735 - 746.

58. Chesebro, B., R. Race, K. Wehrly, J. Nishio, M. Bloom, D. Lechner, S. Bergstrom, K. Robbins, L. Mayer, J. M. Keith, C. Garon, and A. Hasse. 1985. Identification of scrapie prion protein-specific mRNA in scrapie-infected brain. Nature. 315:331 - 333.

59. Carlson, G. A., D. T. Kingsbury, P. A. Goodman, S. Coleman, S. T. Marshall, S. DeArmond, D. Westaway, and S. B. Prusiner. 1986. Linkagae of prion protein and scrapie incubation time genes. Cell. 46:503 - 511 .

60. Hsiao, K., H. F. Baker, T. J. Crow, M. Poulter, F. Owen, J. D. Terwilliger, D. Westaway, J. Ott, and S. B. Prusiner. 1989. Linkage of a prion protein missense variant to Gerstmann-Straussler syndrome. Nature. 338:342 - 345

61. Prusiner, S. B., M. Scott, D. Foster, K.-M. Pan, D. Groth, C. Mirenda, M. Torchia, S.-L. Yang, D. Serban, G. A. Carlson, P. C. Hoppe, D. Westaway, and S. J. DeArmond. 1990. Transgenic studies implicate interactions between homologous PrP isoforms in scrapie prion replication. Cell. 63:673 - 686 .

62. Lasmezas, C. I., J.-P. Deslys, O. Robain, A. Jaegly, V. Beringue, J.M. Peyrin, J.-G. Fournier, J. J. Hauw, J. Rossier, and D. Dormont. 1997. Transmission of the BSE agent to mice in the absence of detectable abnormal prion protein. Science. 275:402 - 405.

63. Hsiao, K. K., M. Scott, D. Foster, D. F. Groth, S. J. DeArmond, and S. B. Prusiner. 1990. Spontaneous neurodegeneration in transgenic mice with mutant prion protein of Gerstmann-Sträussler syndrome. Science. 250:1587 - 1590

64. Westaway, D., S. J. DeArmond, J. Cayetano-Canlas, D. Groth, D. Foster, S.-L. Yang, M. Torchia, G. A. Carlson, and S. B. Prusiner. 1994. Degeneration of skeletal muscle, peripheral nerves, and the central nervous system in transgenic mice overexpressing wild-type prion proteins. Cell. 76:117 - 129 .
65. Weiss, S., M. Famulok, F. Edenhofer, Y.-H. Wang, I. M. Jones, M. Groschup, and E.-L. Winnacker. 1995. Overexpression of active Syrian golden hamster prion protein $\mathrm{PrP}^{\mathrm{C}}$ as a glutathione S-transferase fusion in heterologous systems. J. Virol. 69:4776 - 4783.

66. Cooper, T. G. 1982. Nitrogen metabolism in Saccharomyces cerevisiae, p. 39 - 99. In J. N. Strathern, E. W. Jones, and J. R. Broach (ed.), The molecular biology of the yeast Saccharomyces: metabolism and gene expression, vol. 2. Cold Spring Harbor Laboratory, Cold Spring Harbor.

67. Magasanik, B. 1992. Regulation of nitrogen utilization, p. 283 - 317. In E. W. Jones, J. R. Pringle, and J. R. Broach (ed.), The molecular and cellular biology of the yeast Saccharomyces, 2 nd ed, vol. 2. Cold Spring Harbor Laboratory Press, Cold Spring Harbor, N.Y.

68. Drillien, R., and F. Lacroute. 1972. Ureidosuccinic acid uptake in yeast and some aspects of its regulation. J. Bacteriol. 109:203 - 208.

69. Drillien, R., M. Aigle, and F. Lacroute. 1973. Yeast mutants pleiotropically impaired in the regulation of the two glutamate dehydrogenases. Biochem. Biophys. Res. Comm. 53:367 - 372.

70. Courchesne, W. E., and B. Magasanik. 1988. Regulation of nitrogen assimilation in Saccharomyces cerevisiae: roles of the URE2 and GLN3 genes. J. Bacteriol. 170:708 - 713.

71. Xu, S., D. A. Falvey, and M. C. Brandriss. 1995. Roles of URE2 and GLN3 in the proline utilization pathway in Saccharomyces cerevisiae. Mol. Cell. Biol. 15:2321 - 2330.

72. Turoscy, V., and T. G. Cooper. 1987. Ureidosuccinate is transported by the allantoate transport system in Saccharomyces cerevisiae. J. Bacteriol. 169:2598 - 2600.

73. Rai, R., F. Genbauffe, H. Z Lea, and T. G. Cooper 1987. Transcriptional regulation of the DAL5 gene in Saccharomyces cerevisiae. J. Bacteriol. 169:3521 - 3524.

74. Wickner, R. B. 1996. Prions and RNA viruses of Saccharomyces cerevisiae. Ann. Rev. Genet. 30:109-135.

75. Masison, D.C., M.-L. Maddelein, and R.B. Wickner 1997. The prion model for [URE3] of yeast: Spontaneous generation and requirements for propagation. PNAS 94: 12503 - 12508.

76. Harris, D.A. Prions: Molecular and Cellular Biology. Horizon Scientific Press, Wymondham, UK

77. Edskes, H. K., V. T. Gray, and R. B. Wickner. 1999. The [URE3] prion is an aggregated form of Ure2p that can be cured by overexpression of Ure2p fragments. Proc. Natl. Acad. Sci. USA. 96:1498 - 1503.

78. Taylor, K. L., N. Cheng, R. W. Williams, A. C. Steven, and R. B. Wickner. 1999. Prion domain initiation of amyloid formation in vitro from native Ure2p. Science. 283: 1339 - 1343.

79. King, C.-Y., P. Tittmann, H. Gross, R. Gebert, M. Aebi, and K. Wuthrich 1997. Prion-inducing domain 2-114 of yeast Sup35 protein transforms in vitro into amyloid-like filaments. Proc.Natl. Acad. Sci. USA. 94: 66186622.

80. Glover, J.R., A. S. Kowal, E. C. Shirmer, M. M. Patino, J-J. Liu, and S. Lindquist. 1997. Self-seeded fibers formed by Sup35, the protein determinant of [PSI+], a heritable prion-like factor of S. cerevisiae. Cell. 89: 811 - 819 


\section{Further Reading}

Caister Academic Press is a leading academic publisher of advanced texts in microbiology, molecular biology and medical research. Full details of all our publications at caister.com

- MALDI-TOF Mass Spectrometry in Microbiology Edited by: M Kostrzewa, S Schubert (2016) www.caister.com/malditof

- Aspergillus and Penicillium in the Post-genomic Era Edited by: RP Vries, IB Gelber, MR Andersen (2016) www.caister.com/aspergillus2

- The Bacteriocins: Current Knowledge and Future Prospects Edited by: RL Dorit, SM Roy, MA Riley (2016)

www.caister.com/bacteriocins

- Omics in Plant Disease Resistance Edited by: V Bhadauria (2016) www.caister.com/opd

- Acidophiles: Life in Extremely Acidic Environments Edited by: R Quatrini, DB Johnson (2016) www.caister.com/acidophiles

- Climate Change and Microbial Ecology: Current Research and Future Trend

Edited by: J Marxsen (2016)

www.caister.com/climate

- Biofilms in Bioremediation: Current Research and Emerging Technologies

Edited by: G Lear (2016)

www.caister.com/biorem

- Microalgae: Current Research and Applications Edited by: MN Tsaloglou (2016) www.caister.com/microalgae

- Gas Plasma Sterilization in Microbiology: Theory, Applications, Pitfalls and New Perspectives Edited by: H Shintani, A Sakudo (2016) www.caister.com/gasplasma

- Virus Evolution: Current Research and Future Directions Edited by: SC Weaver, M Denison, M Roossinck, et al. (2016) www.caister.com/virusevol

- Arboviruses: Molecular Biology, Evolution and Control Edited by: N Vasilakis, DJ Gubler (2016) www.caister.com/arbo

- Shigella: Molecular and Cellular Biology Edited by: WD Picking, WL Picking (2016) www.caister.com/shigella

-Aquatic Biofilms: Ecology, Water Quality and Wastewater Treatment

Edited by: AM Romaní, H Guasch, MD Balaguer (2016)

www.caister.com/aquaticbiofilms

- Alphaviruses: Current Biology

Edited by: S Mahalingam, L Herrero, B Herring (2016)

www.caister.com/alpha

- Thermophilic Microorganisms

Edited by: F Li (2015)

www.caister.com/thermophile
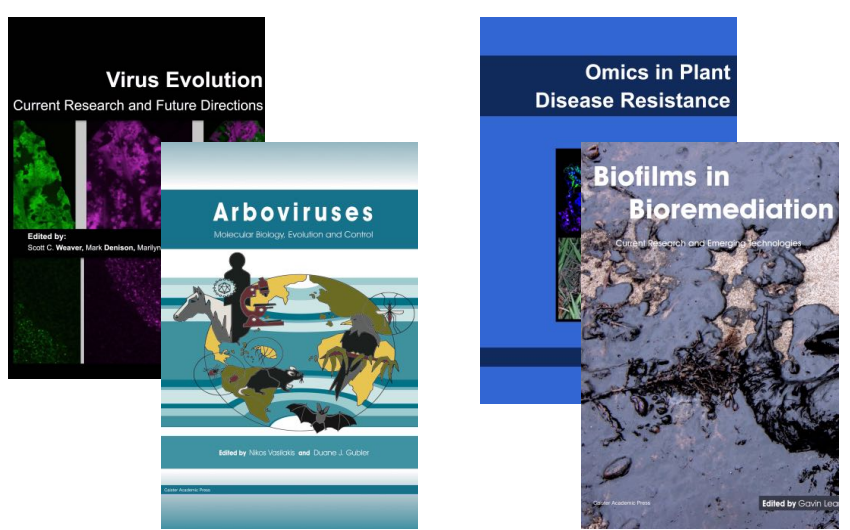
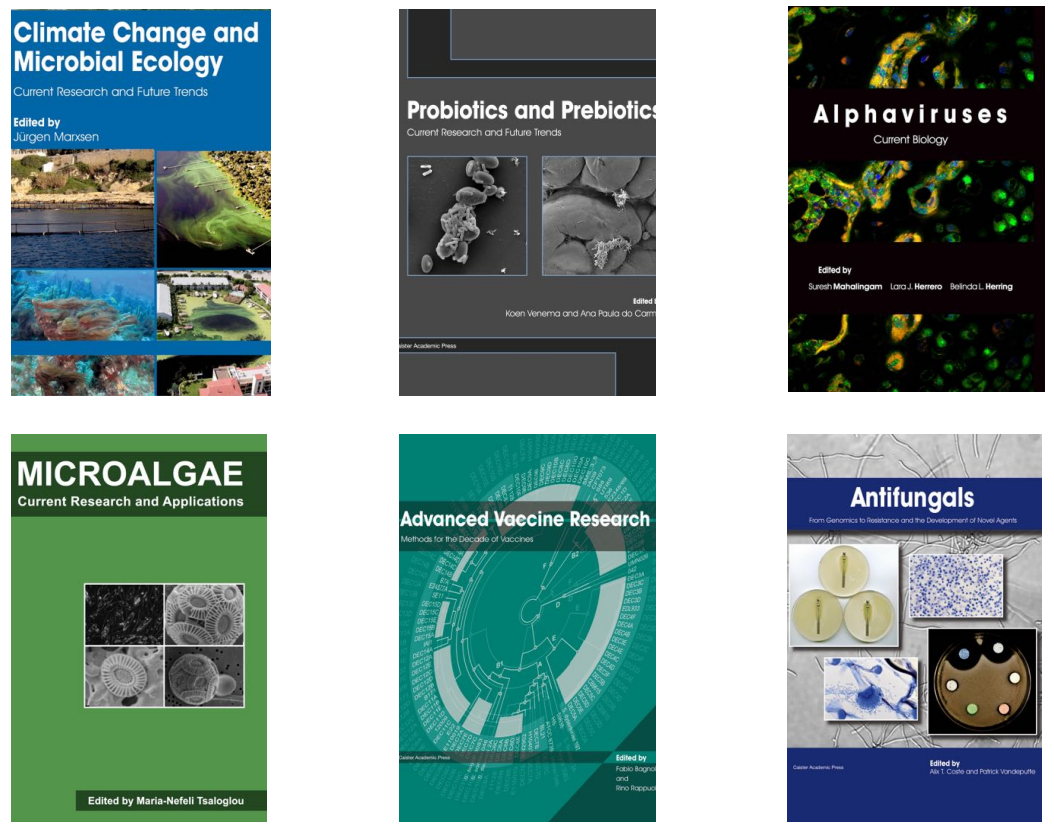

- Flow Cytometry in Microbiology: Technology and Applications Edited by: MG Wilkinson (2015) www.caister.com/flow

- Probiotics and Prebiotics: Current Research and Future Trends Edited by: K Venema, AP Carmo (2015) www.caister.com/probiotics

- Epigenetics: Current Research and Emerging Trends Edited by: BP Chadwick (2015) www.caister.com/epigenetics2015

- Corynebacterium glutamicum: From Systems Biology to Biotechnological Applications

Edited by: A Burkovski (2015)

www.caister.com/cory2

- Advanced Vaccine Research Methods for the Decade of Vaccines

Edited by: F Bagnoli, R Rappuoli (2015)

www.caister.com/vaccines

- Antifungals: From Genomics to Resistance and the Development of Novel Agents

Edited by: AT Coste, P Vandeputte (2015)

www.caister.com/antifungals

- Bacteria-Plant Interactions: Advanced Research and Future Trends Edited by: J Murillo, BA Vinatzer, RW Jackson, et al. (2015) www.caister.com/bacteria-plant

\section{- Aeromonas}

Edited by: J Graf (2015)

www.caister.com/aeromonas

- Antibiotics: Current Innovations and Future Trends

Edited by: S Sánchez, AL Demain (2015)

www.caister.com/antibiotics

- Leishmania: Current Biology and Contro Edited by: S Adak, R Datta (2015) www.caister.com/leish2

- Acanthamoeba: Biology and Pathogenesis (2nd edition) Author: NA Khan (2015)

www.caister.com/acanthamoeba2

- Microarrays: Current Technology, Innovations and Applications Edited by: Z He (2014)

www.caister.com/microarrays2

- Metagenomics of the Microbial Nitrogen Cycle: Theory, Methods and Applications

Edited by: D Marco (2014)

www.caister.com/n2 